\title{
Pertunjukan Wayang Kulit Madya Lakon Aji Pamasa Sanggit Ki Purbo Asmoro
}

(The Play Aji Pamasa Sanggit in Ki Purbo Asmoro Wayang Kulit Madya Performance)

\author{
Sapta Adi Santoso, Tatik Harpawati \\ Jurusan Seni Pedalangan, Fakultas Seni Pertunjukan, \\ Institut Seni Indonesia Surakarta \\ Email: sapto6440@gmail.com, tatikharpawati@gmail.com
}

\begin{abstract}
This paper discusses the puppet shapes, movements, musical accompaniment, and the story-telling of Aji Pamasa play by Ki Purbo Asmoro. This research uses descriptive qualitative method in which Murtiyoso concept of puppetry medium is further explored. The data collection method used was observation, note-taking, and sorting techniques. The method used in the data analysis phase was library research. This study has concluded that the Wayang Madya presentation of Aji Pamasa play by Ki Purbo Asmoro has been adapted to the shapes of the puppets and the musical accompaniment.
\end{abstract}

Keywords: wayang madya, Aji Pamasa, puppetry medium, Ki Purbo Asmoro

\begin{abstract}
Abstrak
Tulisan ini membahas tentang bentuk wayang, gerak wayang, iringan karawitan, dan penceritaan lakon Aji Pamasa sanggit Ki Purbo Asmoro. Konsep medium pedalangan Murtiyoso digunakan sebagai landasan dalam penelitian ini. Penelitian ini menggunakan metode deskriptif kualitatif. Metode pengumpulan data dilakukan dengan teknik simak, teknik catat, dan teknik pilah. Metode yang digunakan dalam tahap analisis data adalah metode kepustakaan (bybrary methods). Penelitian ini menemukan simpulan bahwa sajian pertunjukan wayang madya lakon Aji Pamasa sanggit Ki Purbo Asmoro telah mengalami penyesuaian dalam hal bentuk boneka wayang dan iringan pakeliran.
\end{abstract}

Kata kunci: wayang madya, Aji Pamasa, medium pedalangan, Ki Purbo Asmoro

\section{Pengantar}

Apabila ditinjau dari bentuk pertunjukannya, seni pedalangan memiliki berbagai ragam bentuk antara lain Wayang Bèbèr, Wayang Kulit (Purwa), Wayang Madya, Wayang Gedhog, dan Wayang Wasana (Murtiyoso \& dkk., 2007, pp. 1-2). Dari kelima bentuk pertunjukan wayang tersebut, yang paling berkembang sampai sekarang ialah Wayang Kulit Purwa. Dengan demikian ketika saat ini hadir bentuk pertunjukan wayang yang lain, itu merupakan sebuah kejutan dan pantas mendapat perhatian lebih.

Berkaitan dengan hadirnya bentuk pertunjukan wayang yang sudah mulai ditinggalkan dan jarang kita temui, pertunjukan Wayang Madya lakon Aji Pamasa oleh Ki Purbo Asmoro merupakan fenomena yang mengundang perhatian. Di tengah maraknya inovasi bentukbentuk pertunjukan wayang yang berbasis pada pertunjukan wayang purwa, seperti wayang sandosa, wayang animasi, wayang sinema, dan lain sebagainya, pada tahun 2018 Ki Purbo Asmoro hadir dengan menyajikan bentuk pertunjukan 
Wayang Madya lakon Aji Pamasa. Data yang langka ini sangat sayang kalau diabaikan, oleh karena itu peneliti tertarik untuk menelisiknya lebih jauh. Ada beberapa tujuan dalam penelitian ini, namun tujuan pendokumentasian dan melihatnya sebagai alternatif sajian wayang menjadi tujuan utama.

Berdasarkan tujuan tersebut maka tulisan ini berupaya mendeskripsikan beberapa hal antara lain bentuk wayang, gerak wayang, iringan karawitan, dan penceritaan lakon Aji Pamasa Ki Purbo Asmoro.

\section{Konsep Medium Pedalangan}

Pendeskripsian bentuk wayang, gerak wayang, iringan karawitan, dan penceritaan lakon Aji Pamasa Ki Purbo Asmoro dalam penelitian ini berdasarkan konsep tentang medium pedalangan seperti yang dikemukakan oleh Murtiyoso, dkk. (2007) dalam buku Teori Pedalangan: Bunga Rampai elemen-elemen Dasar Pakeliran.

Murtiyoso, dkk. (2007, p. 4) mengatakan bahwa seni pedalangan memiliki empat macam medium yang berupa (1) bahasa, (2) suara, (3) gerak, dan (4) rupa. Masing-masing medium ini dalam penerapannya tidak dapat dipisah-pisahkan, di antara medium satu dan lainnya saling berkait dan saling mendukung menjadi suatu kesatuan yang membentuk pertunjukan wayang secara utuh.

Bahasa merupakan bahan baku yang digarap sebagai media ungkap dalam wujud wacana dan vokal dalang. Wacana dalang, yang dalam pedalangan disebut basa padhalangan ialah bahasa Jawa yang digunakan khusus dalam seni pedalangan. Di dalam seni pedalangan, ungkapan melalui bahasa ini dapat berupa deskripsi atau narasi (janturan, pocapan), dan dialog (ginem) ataupun monolog (ngudarasa) tokoh wayang. Selain itu bahasa juga digunakan sebagai media ungkap vokal dalang dalam bentuk sulukan dan kombangan (Murtiyoso \& dkk., 2007, p. 4).

Suara adalah bahan baku yang digarap sebagai sarana ungkap, baik wacana, vokal dalang, maupun karawitan pakeliran. Wacana yang dimaksud di sini bukan sekedar ungkapan bahasa sebagai sarana komunikasi, akan tetapi ungkapan wacana itu harus mengacu pada wujud, karakter, dan suasana tokoh wayang. Dalam hal ini pengolahan suara sangat menentukan keberhasilan sajian wacana wayang, dengan pengolahan suara yang tepat akan memperjelas perbedaan wujud karakter dan suasana tiap-tiap tokoh. Selain itu vokal dalang juga memerlukan lagu yang merupakan hasil pengolahan suara dalang, dengan lagu vokal akan mendukung tampilan suasana tokoh maupun adegan tertentu. Di sisi lain karawitan pakeliran juga merupakan hasil olahan suara yang berupa ungkapan tembang dan gending. Dengan demikian, suara merupakan bahan yang mutlak harus ada, tanpa ada suara, dalang tidak dapat mengungkapkan kesan estetik melalui suara wacana wayang, vokal, maupun tembang dan gending-gending yang diperlukan (Murtiyoso \& dkk., 2007, p. 4).

Gerak merupakan bahan baku yang diolah sebagai media ekspresi gerak wayang. Salah satu tugas seorang dalang adalah menghidupkan tampilan wayang lewat ekspresi gerak. Penampilan gerak wayang tidak sekedar gerak dalam arti obah (moving), melainkan gerakan yang ekspresif, berkesan hidup dan sesuai dengan karakter wayang yang tampil. Oleh karena itu dalang dalam menggerakkan wayang harus menguasai teknikteknik dasar menggerakkan wayang di antaranya meliputi bentuk, volume, intonasi, tempo, dan kesesuaian dengan iringan. Dengan mengolah gerak melalui bentuk dan penampilan wayang, akan menimbulkan kesan estetik lewat gerak yang nampak hidup. Tanpa gerak dalang tidak dapat mengungkapkan kesan keindahan yang menghidupkan boneka wayang (Murtiyoso \& dkk., 2007, p. 5).

Rupa adalah bahan baku yang diolah sebagai sarana ungkap wujud wayang. Rupa dalam hal ini mencakup tampilan bentuk, warna, dan karakter. Di dalam pedalangan tradisi Jawa, penampilan tokoh wayang dalam suatu sajian pakeliran tidak sekedar menampilkan wayang sesuai dengan wujud wayang dan namanya saja, tetapi perlu mempertimbangkan suasana adegan, suasana tokoh, dan karakternya. Oleh karena itu pada umumnya tokoh-tokoh wayang tertentu yang dianggap mempunyai peran penting, satu tokoh dibuat lebih dari satu, masing-masing mempunyai perbedaan khas yang disebut wanda. Jadi rupa juga merupakan medium yang mutlak harus ada, hubungannya dengan karakter wayang yang ditampilkan dalam lakon. Dengan melihat wujud wayang itulah dalang dapat berekspresi sebagai tokoh yang bersangkutan (Murtiyoso \& dkk., 2007, 
pp. 5-6).

Dilihat dari fungsinya, medium pokok pedalangan ini memiliki dua fungsi yaitu fungsi teknik dan fungsi estetik. Dikatakan memiliki fungsi teknik ketika media ini digunakan untuk mengekspresikan ide-ide melalui bentuk wacana, vokal dalang, gerak wayang, dan karawitan pakeliran. Dikatakan memenuhi fungsi estetik jika medium ini merupakan bahan baku yang digarap untuk mendukung suasana adegan atau peristiwa sesuai dengan kepentingan suasana adegan, suasana tokoh, dan karakter wayang (Murtiyoso \& dkk., 2007, p. 6).

\section{Bentuk Wayang}

Wayang madya dibuat atas prakarsa Mangkunegara IV. Wayang madya pada masa itu memiliki bentuk kepala seperti wayang purwa, tetapi badannya seperti wayang gedhog, (Soetarno, 2004, p. 9). Jika kita berpijak pada deskripsi bentuk wayang madya tadi, maka didapatkan satu kenyataan yang berbeda ketika kita mengamati pertunjukan wayang madya Ki Purbo Asmoro. Dalam pertunjukan wayang madya lakon Aji Pamasa, Ki Purbo Asmoro menggunakan tokoh wayang srambahan (katongan, putren, bambangan, pendhitan, patiban) yang fleksibel dan sesuai dengan interpretasi dalang terhadap sifat/karakter tokoh dalam lakon. Artinya dalam pertunjukan itu tokoh-tokoh wayang dipinjam dari lakon wayang Kulit Purwa.

Adapun tokoh-tokoh wayang dalam pertunjukan wayang kulit madya lakon Aji Pamasa sajian Purbo Asmoro adalah sebagai berikut.

\section{Tokoh Wayang Aji Pamasa}

Tokoh Aji Pamasa atau disebut dengan Kusumawicitra disajikan dengan bentuk tokoh yang lurub atau raut wajah menghadap ke bawah melambangkan sifat lemah lembut. Sesuai dengan watak dan karakter Prabu Aji Pamasa. Tokoh wayang ini digambarkan melalui bentuk wajah bagusan, bentuk tubuh wayang katongan, bentuk bokongan banyakan, memakai makutha, dan sampur yang ada pada tokoh wayang.

Purbo Asmoro menggunakan tokoh wayang Rama bokong banyakan yang biasanya dipakai untuk tokoh Arjunasasra. Pemilihan wayang tersebut didasarkan pada interpretasi bahwa Aji Pamasa merupakan ratu alusan. Raja
Kediri merupakan titisan dari Wisnu maka dipilihlah tokoh Arjunasasra untuk penokohan Aji Pamasa. Bentuk wayang tersebut dipilih Purbo Asmoro (Asmoro, Wawancara 2, 2019) untuk menggambarkan sosok Prabu Aji Pamasa sebagai sosok raja yang berwibawa. Selain itu, bentuk wayang seperti ini juga menggambarkan tokoh berjiwa kesatriya.

Wajahnya yang luruh atau menunduk ke bawah, bentuk hidung mancung, bermata sipit gabahan, pinggang ramping, lengan memakai kelatbahu, jari tangan memakai cincin, dan jangkah kaki sempit. Ciri fisik tersebut mengandung makna bahwa tokoh Aji Pamasa mempunyai sifat dan karakter yang lemah lembut. Berdasarkan hal tersebut dapat diketahui penggunaan tokoh wayang di atas sangat tepat untuk memvisualisasikan peran Prabu Aji Pamasa yang berparas tampan, gagah, dan sakti. Hal ini diperjelas dengan pernyataan Bambang Suwarno (Suwarno, 2015, p. 473), bahwa wanda wayang dengan penampilan lurub biasanya memiliki antawacana dengan warna suara yang berat dan bernada rendah, perlahan dan mantap. Tokoh wayang Aji Pamasa seperti yang dimaksud Purbo Asmoro ini dapat dilihat pada gambar 1.

\section{Tokoh Wayang Tambakbaya}

Tokoh wayang Patih Tambakbaya dengan bentuk fisik raut wajah lurub warna hitam, bentuk mata telengan, rambut terurai di pundak, memakai selendang, memiliki kuku panjang, lengan memakai kelatbahu, pergelangan tangan memakai gelang dan

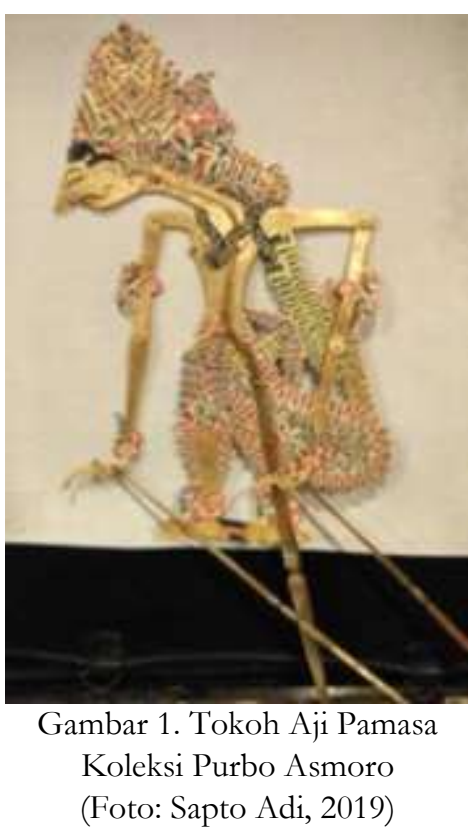


kaki jangkahan. Ciri-ciri di atas menggambarkan ia memiliki jiwa kesatria, teguh pendirian, berbadan besar bermakna ia sosok patih yang kuat dalam menghadapi berbagai masalah. Purbo Asmoro mengimajinasikan tokoh dengan karakter yang dimaksud dalam lakon tersebut dengan wayang gagaban, maka dipilihlah tokoh wayang wadya jodhipati (Asmoro, Wawancara 2, 2019). Tokoh wayang Tambakbaya seperti yang dimaksud Purbo Asmoro ini dapat dilihat pada gambar 2.

\section{Tokoh Wayang Wirabaya}

Tokoh Wirabaya dalam lakon Aji Pamasa ini, Ki Purbo Asmoro meminjam tokoh Aswatama landhak kreasi yang memiliki kemiripan sifat, watak, dan karakter wayang antagonis (Asmoro, Wawancara 2, 2019). Dilihat dari bentuk dan warna wajah, tokoh Wirabaya ini adalah seorang yang sangat temperamental atau mudah marah. Hal tersebut digambarkan melalui wajahnya yang berwarna merah serta raut wajah yang menggambarkan watak serakah, kejam, dan jahat. Kejahatan Wirabaya tampak pada tindakannya ketika melaksanakan perintah raja. Tanpa pikir panjang dan tanpa mempertimbangkan baik dan benarnya perintah sang raja, ia langsung membunuh Resi Ajar Tejalaku. Tokoh wayang Wirabaya seperti yang dimaksud Purbo Asmoro ini dapat dilihat pada gambar 3.

\section{Tokoh Wayang Kanigara dan Kaniyasa}

Tokoh Kanigara dan Kaniyasa diinterpretasikan Purbo Asmoro (Asmoro

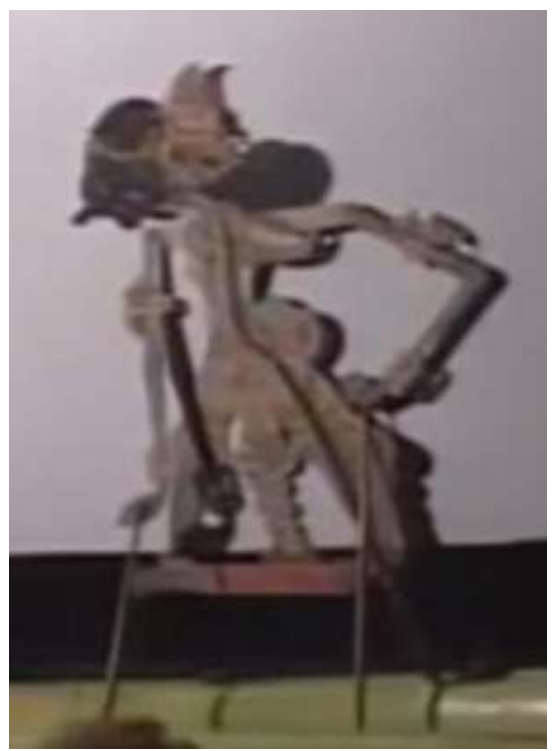

Gambar 2. Tokoh Tambakbaya

(Repro, Video Lakon Aji Pamasa)
Wawancara 2., 2019) sebagai tokoh halus/alusan. Sehingga dalam lakon Aji Pamasa ini, digunakan wayang bambangan dengan bentuk bokongan rapékan sebagai ciri fisik wayang madya.

Wujud Kanigara dan Kaniyasa dengan raut wajah luruh atau menunduk ke bawah menggambarkan sosok yang lemah lembut dan baik hati. Kaki jangkahan melambangkan ia adalah sosok ksatria yang memiliki keteguhan hati. Perbedaan kedua tokoh terletak pada selendang yang dipakai tokoh Kanigara. Tokoh wayang Kanigara dan Kaniyasa seperti yang dimaksud Purbo Asmoro ini dapat dilihat pada gambar 4 dan gambar 5.

Ciri fisik yang digambarkan dalam gambar 4 dan 5 sangat cocok untuk menggambarkan watak dan karakter tokoh Kanigara dan Kaniyasa dalam sajian pertunjukan wayang madya. Rupa-rupanya dalam meminjam kedua tokoh wayang ini, Purbo Asmoro sangat memperhatikan penyataan Naryacarita yang dikutip oleh Bambang Suwarno (2015, p. 75), bahwa kelonggaran dalam memilih wanda wayang yang digunakan dalam pakeliran yang penting enak dipakai untuk sabetan dan mungguh dalam sajian lakon. Kedua tokoh tersebut merupakan murid Resi Tejalaku yang berbudi luhur dan patuh terhadap gurunya. Jiwa ksatrianya terlihat ketika ia membela kematian gurunya walaupun pada akhirnya ia juga ikut mati di tangan Tumenggung Wirabaya.

\section{Tokoh Wayang Saktrini}

Tokoh Saktrini adalah raksasa wanita.

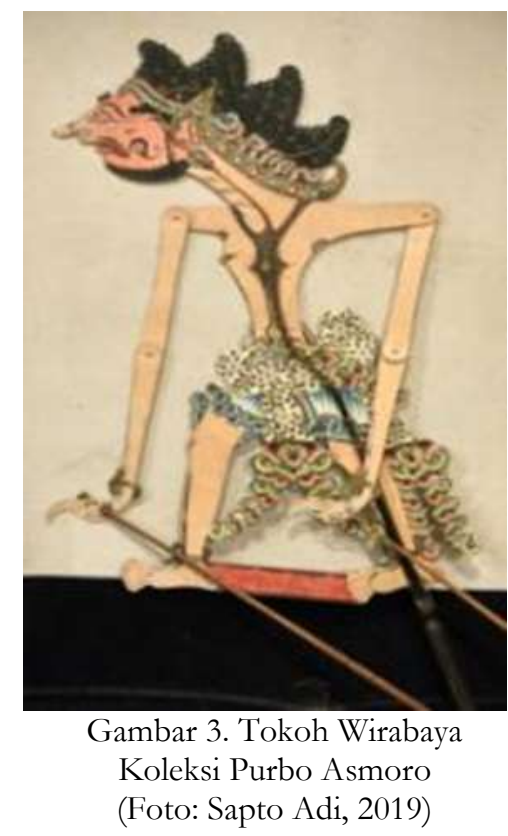


Tokoh Saktrini dapat dilihat pada gambar 6. Tokoh ini berbentuk raksasa wanita berwajah sangar, mempunyai gigi taring panjang, rambut terurai panjang, payudara yang terbuka, bagian bawah mengenakan pakaian, dan bentuk kaki jangkahan. Berdasarkan ciri fisik tersebut maka tokoh wayang di atas sangat cocok untuk menggambarkan watak Saktrini yang serakah, jahat, dan kejam. Peminjaman tokoh ini didasarkan penafsiran Purbo Asmoro (Asmoro, Wawancara 2, 2019) terhadap tokoh Saktrini yang digambarkan sebagai lelembut atau makhluk siluman beserta karakternya. Oleh karena itu dipilihlah wanda wayang yang sesuai dengan deskripsi tipologi dan karakter tokoh (Suwarno, 2015, p. 76). Perilaku serakah, jahat, dan kejam dari tokoh Saktrini terlihat pada adegan
Prabu Aji Pamasa yang terlibat konflik ketika berjalan menuju hutan Pengging yang merupakan wilayah kekuasaannya. Saktrini dengan wujud tersebut juga mempunyai watak sebagai perempuan penggoda, ia berusaha menggoda Aji Pamasa.

\section{Tokoh Wayang Ditya Saktriya}

Tokoh Saktriya di dalam lakon Aji Pamasa ditampilkan dengan bentuk raksasa. Purbo Asmoro (Asmoro, Wawancara 2, 2019) menyatakan bahwa penggunaan tokoh raksasa untuk tokoh Ditya Saktriya menganut balungan konvensional yang menyebutkan bahwa bentuk dari Saktriya adalah raksasa. Gambar 7 merupakan penggambaran wujud tokoh Ditya Saktriya. Wujud fisik Ditya Saktriya ialah raksasa besar, rambut terurai dari atas

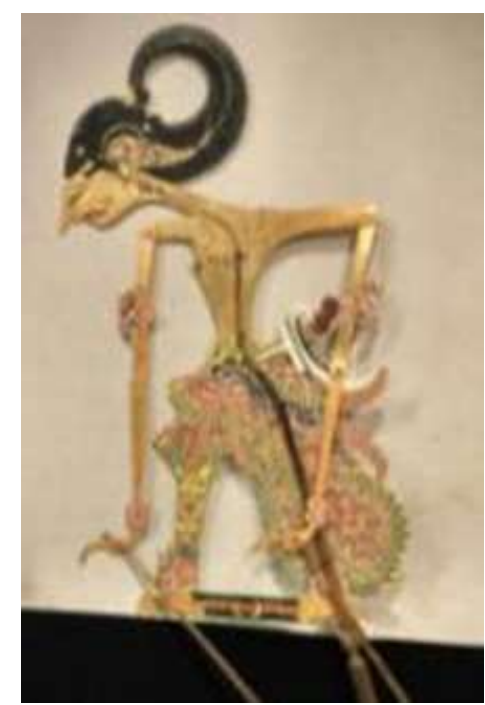

Gambar 4. Tokoh Kaniyasa Koleksi Purbo Asmoro (Foto: Sapto Adi, 2019)

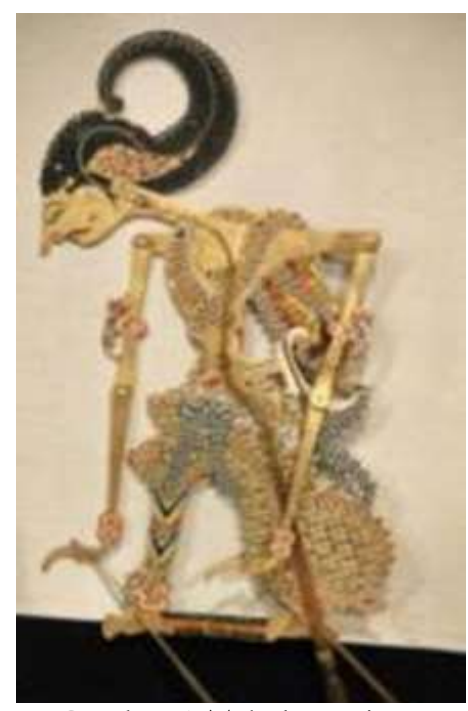

Gambar 5. Tokoh Kanigara Koleksi Purbo Asmoro (Foto: Sapto Adi, 2019)

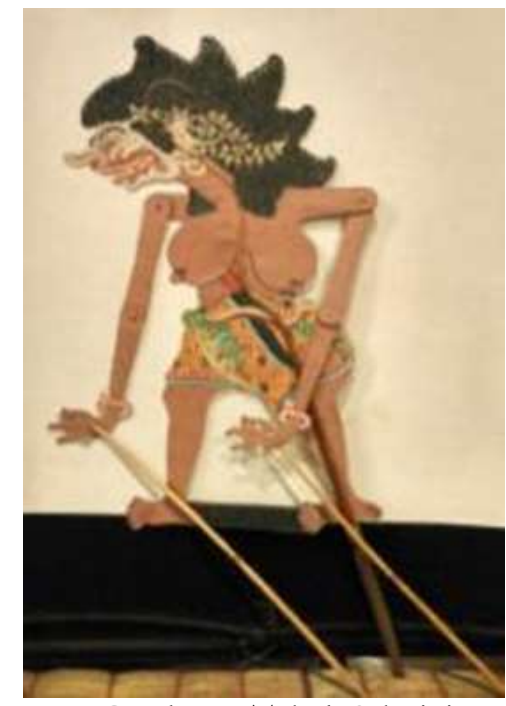

Gambar 6. Tokoh Saktrini Koleksi Purbo Asmoro (Foto: Sapto Adi, 2019)

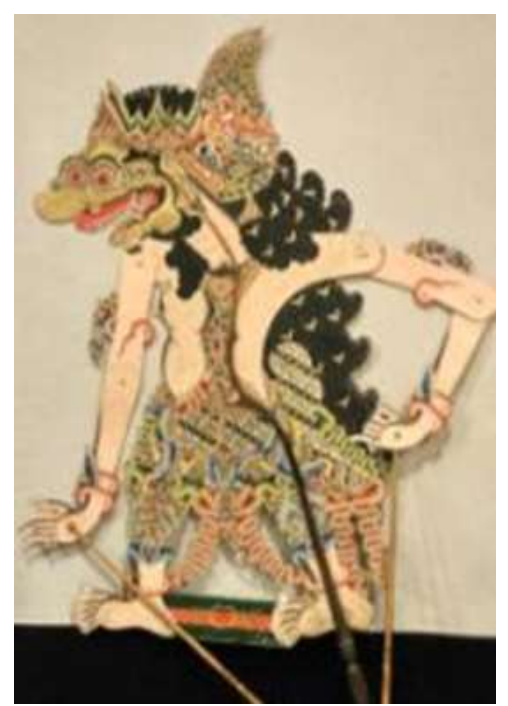

Gambar 7. Tokoh Saktriya Pamasa Koleksi Purbo Asmoro (Foto: Sapto Adi, 2019) 
kepala hingga kaki, bertubuh besar, mempunyai gigi taring, memakai jamang, kaki jangkahan, bentuk mata telengan, dan raut wajah menggambarkan sosok yang kejam. Berdasarkan bentuk fisik tokoh di atas maka tokoh wayang tersebut sangat cocok untuk mewakili watak dan sifat Ditya Saktriya yaitu serakah akan kekuasaan, kejam, dan berusaha membunuh yang menjadi lawannya. Penggunaan tokoh raksasa untuk Ditya Saktriya oleh Purbo Asmoro didasarkan pada sifat, watak, dan karakter sang tokoh. Selain itu juga didasarkan dari nama depan Ditya yang memiliki makna raksasa. Ditya Saktriya dalam lakon berperan sebagai penghalang Aji Pamasa.

\section{Tokoh Wayang Ajar Tejalaku}

Tokoh Tejalaku diwujudkan dengan bentuk pandhita gabahan yang bersifat baik hati, maka digunakan tokoh wayang pandhitan kedhelèn (Asmoro, Wawancara 2, 2019). Gambar 8 merupakan wujud Ajar Tejalaku seorang pendeta di Gunung Kelud seperti diinterpretasikan Purbo Asmoro. Bentuk fisik Ajar Tejalaku ialah bentuk wayang pandhita, bentuk wajah lurub atau menghadap ke bawah melambangkan ia sosok yang baik hati. Penggunaan tokoh tersebut sebagai Ajar Tejalaku dengan pertimbangan visualisasi sifat, watak, dan karakter Tejalaku. Ajar Tejalaku berperan sebagai tokoh guru yang mempunyai murid banyak. Ia diduga akan menandingi kekuasaan Prabu Aji Pamasa di Mamenang dikarenakan pengaruhnya yang besar terhadap rakyat

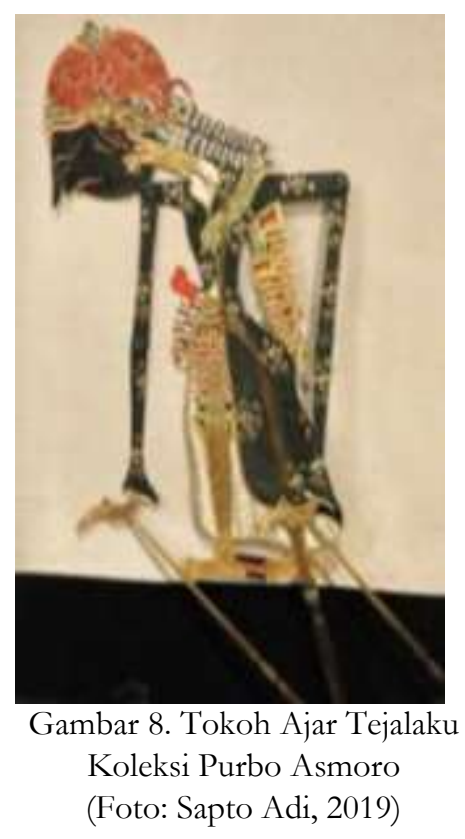

\section{Tokoh Wayang Naga Kunta dan Naga Kunti}

Tokoh Naga Kunta dan Kunti diwujudkan dengan bentuk tokoh wayang ular besar. Perbedaan yang terdapat pada kedua tokoh terdapat pada bentuk. Naga Kunta diwakili dengan wujud ular besar sebagai ular jantan, sedangkan Naga Kunti digambarkan dengan bentuk ular yang lebih kecil dibandingkan Naga Kunta sebagai ular betina. Penafsiran penokohan di atas berdasarkan deskripsi tokoh di dalam lakon (Asmoro, Wawancara 2, 2019). Gambar 9 adalah perwujudan Naga Kunta (kanan) dan Naga Kunti (kiri).

\section{Tokoh Wayang Kalayuwati}

Tokoh Kalayuwati diwujudkan dengan tokoh Sarpakenaka jarikan, hal itu didasarkan pada interpretasi dalang terhadap sifat dan karakter tokoh Kalayuwati (Asmoro, Wawancara 2, 2019). Tokoh wayang pada gambar 10 merupakan wujud gambaran tokoh Bathari Kalayuwati penunggu hutan Krendhawahana. Tokoh ini digambarkan dengan bentuk fisik wayang perempuan dengan raut wajah seperti raseksi. Walaupun bentuk fisik raseksi tetapi karakter yang dibawakan ialah sebagai penengah atau pemberi solusi. Peran Kalayuwati dalam lakon ini ialah sebagai penunggu hutan Krendhawahana dan penengah konflik. Ketika Aji Pamasa mengejar Lembu Andanu sampai ke hutan Krendhawahana ia bertemu dengan Bathari Kalayuwati.

\section{Tokoh Wayang Ken Mastura}

Tokoh Ken Mastura diwujudkan dengan bentuk fisik wayang Sinta (lihat gambar 11), hal ini terkait dengan pengimajinasian dalang terhadap karakter Ken Mastura dalam lakon Aji Pamasa (Asmoro, Wawancara 2, 2019). Tokoh Ken Mastura divisualisasikan dengan bentuk wayang

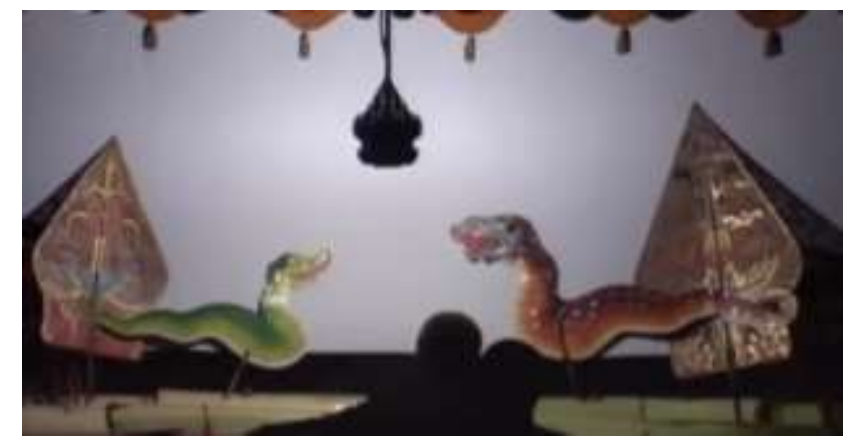

Gambar 9. Tokoh Naga Kunta dan Kunti

(Repro, VCD lakon Aji Pamasa sajian Purbo Asmoro) 
putrèn, raut wajah luruh, berparas cantik, rambut terurai panjang, dan bentuk tubuh ramping. Watak dan karakter tokoh Ken Mastura yang lemah lembut, baik hati, dan setia diwakili oleh bentuk fisik wayang tersebut. Ken Mastura berperan sebagai istri dari Kanigara. Ia sosok istri yang sangat setia, kesetiaannya tercermin ketika Kanigara mati dibunuh oleh Wirabaya. Ia ikut bunuh diri demi membela kematian suaminya.

\section{Tokoh Wayang Sakila dan Sakili}

Purbo Asmoro (2019) menyatakan bahwa tokoh Sakila dan Sakili merupakan tokoh tambahan dalam lakon Aji Pamasa yang diwakili dengan wayang brayud untuk peran rakyat. Gambar 12 menunjukkan tokoh Demang Sakila (kanan) dan

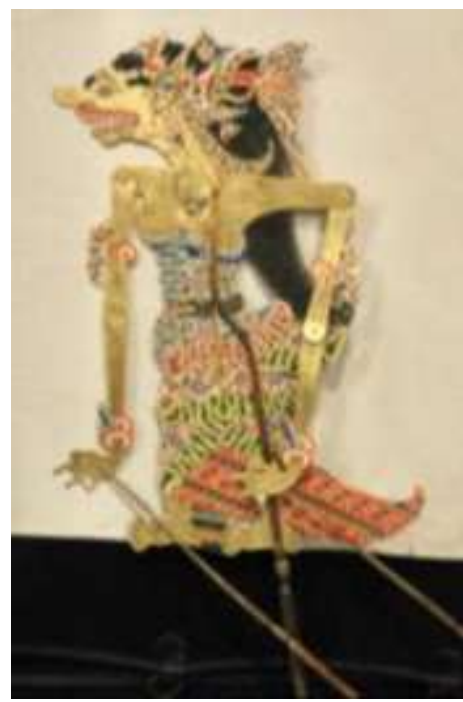

Gambar 10. Tokoh Kalayuwati Koleksi Purbo Asmoro (Foto: Sapto Adi, 2019)

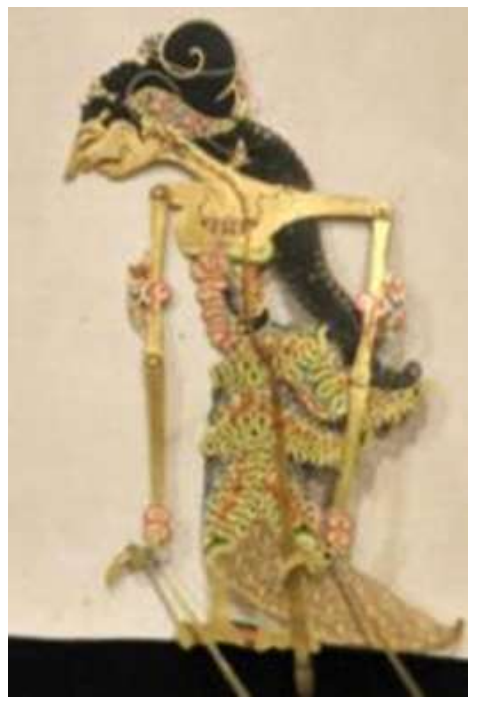

Gambar 11. Tokoh Ken Mastura

Koleksi Purbo Asmoro

(Foto: Sapto Adi, 2019)
Nyai Sakili (kiri). Kedua tokoh tersebut merupakan tokoh tambahan untuk pelengkap dalam lakon. Sakila dan Sakili merupakan tokoh rakyat jelata, digambarkan dengan bentuk wayang sepasang suami istri yang menggendong anak berjumlah banyak di tubuhnya (wayang brayud). Dalam lakon ini mereka berperan sebagai rakyat yang kesusahan. Suatu ketika mereka berjumpa dengan Kuntana (wujud lain Naga Kunta) yang memberi batu timpuru. Dengan pemberian batu tersebut Sakila dan Sakili tidak terkena bencana banjir lahar yang melanda Mamenang.

\section{Bentuk Sabet (Gerakan Wayang)}

Sabet merupakan unsur pakeliman yang meliputi semua gerak dan penampilan boneka wayang di atas panggungan atau kelir atau layar yang disajikan oleh dalang (Murtiyoso, 1981, p. 13). Sabet menurut Bambang Suwarno yang dikutip oleh Sugeng Nugroho (Nugroho, 2012, p. 433), dikelompokkan menjadi dua jenis: sabet representatif dan sabet tematik. Sabet representatif adalah bentuk sabet yang mempresentasikan gerakgerik boneka wayang, misalnya berjalan, melompat, terbang, bertapa, bermesraan, menggendong dan sebagainya. Sedangkan sabet tematik adalah bentuk sabet yang mengungkapkan bayangan, perasaan, lamunan tokoh wayang mengenai peristiwa masa lampau.

Bentuk sabet yang diterapkan oleh Purbo Asmoro dalam sajian wayang madya lakon Aji Pamasa dapat dikatakan menggunakan konsep sabet representatif dan sabet tematik. Sabet representatif dalam sajian tersebut diantaranya, yaitu cepengan, tanceban, solah, dan entas-entasan. Selain itu Purbo Asmoro juga menggunakan teknik sabet tematik, hal tersebut terlukis dalam adegan-adegan tertentu

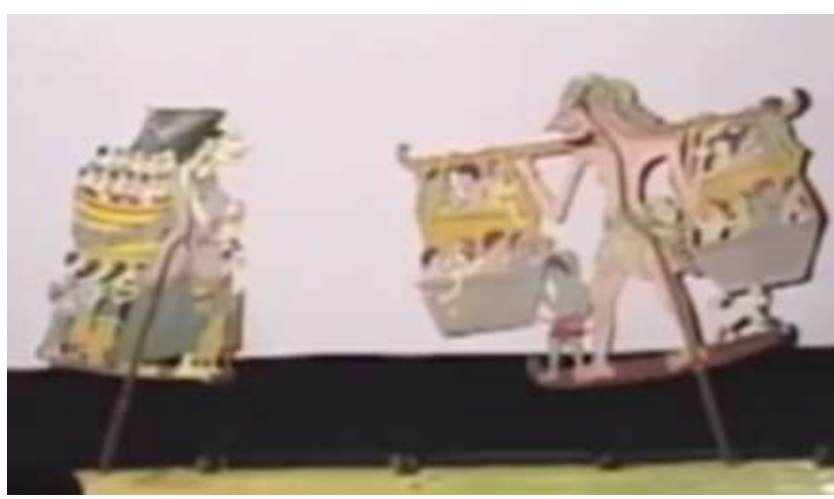

Gambar 12. Tokoh Sakila dan Sakili

(Repro, VCD lakon Aji Pamasa sajian Purbo Asmoro) 
yang mewakili pengungkapan perasaan batin tokoh. Berdasarkan hasil penelitian bentuk sabet tematik dalam lakon Aji Pamasa yang disajikan Ki Purbo Asmoro hanya terdapat dalam flashback saja, selain adegan itu digunakan sabet reprensentatif.

\section{Bentuk Iringan Pakeliran}

Media musik (karawitan) di dalam dunia pakeliran sering disebut dengan iringan pakeliran atau karawitan pakeliran. Karawitan pakeliran memiliki peran penting di dalam sajian wayang kulit yaitu untuk menciptakan suasana-suasana tertentu dan mendukung dramatisasi di dalam pakeliran. Karawitan wayang atau gending-gending wayangan meliputi gending-gending untuk mengiringi adegan, suluk yang meliputi: pathetan, sendhon, dan ada-ada, tembang, dhodhogan dan keprakan (Soetarno et al., 2007, p. 49).

Soetrisno (Soetrisno, 1985, p.

mengatakan bentuk iringan wayang madya sama seperti wayang purwa tetapi dengan laras pélog semua termasuk sulukannya. Dalam pertunjukan wayang madya lakon Aji Pamasa sajian Purbo Asmoro digunakan gending-gending dengan laras sléndro dan pélog. Penggunaan kedua laras dalam sajian ini dengan pertimbangan agar akrab di telinga penonton. Berikut keterangan Purbo Asmoro mengenai penggunaan gending dengan laras sléndro dan pélog dalam lakon Aji Pamasa.

Spontanitas nék kaé, lha piyé latihan aé ora aku. Karena kebutuhan sekarang. Penonton itu kan tidak begitu nggagas nék apa madya ki kudu pélog, sing penting laras ki sing akrab dengan mereka gitu saja. Ya faktoré faktor bèn akrab kadhang pélog kadhang ya sléndro. Dadi iringané ya pleg kaya iringan wayang purwa (Asmoro, Wawancara 1, 2019).

Terjemahan:

('Spontanitas kalau itu, ya harus bagaimana latihan saja tidak. Karena kebutuhan sekarang. Penonton itu kan tidak begitu memperhatikan kalau madya itu haru pélog, yang penting nada yang akrab dengan mereka begitu saja. Ya faktornya supaya lebih akrab kadang pélog kadang ya sléndro. Jadi iringannya ya sama persis dengan iringan wayang purwa').

Berdasarkan kutipan wawancara dengan narasumber utama tadi didapat keterangan bahwa penggunaan iringan dibuat secara spontanitas. Hal ini juga diperjelas dengan pernyataan Bagus
Danang Surya Putra (Putra, 2019) yang berperan sebagai pengrawit (penggender) pada pertunjukan tersebut yang menyatakan bahwa:

"Pas kaé ora kencan kok, ya mung Pak. Purbo ning panggung ngèki orèk-orèkan urutan iringane"

Terjemahan:

(Pada saat itu tidak ada kesepakatan, ya hanya Pak Purbo di atas panggung memberi catatan yang berisi urutan iringan).

Purbo Asmoro (Wawancara 2, 2019) menyatakan bahwa penggunaan iringan/karawitan pada lakon Aji Pamasa tidak mengacu pada pakem yang sudah ada khususnya iringan pertunjukan wayang madya. Penggunaan dua laras gamelan yaitu laras sléndro dan pélog berdasarkan pada kebutuhan pentas dan suasana yang dihasilkan dari iringan. Seperti misalnya penggunaan Ldr. Sobrang Sl. Nem menciptakan suasana agung, regu, dan remeng ketika adegan Kerajaan Mamenang. Penggunaan gending untuk menciptakan suasana sedih disajikan gending dengan nada-nada tlutur/sedih. Penggunaan gending tersebut berdasarkan pada konvensi yang telah disepakati oleh kalangan seniman karawitan dan pedalangan yang masih berlaku hingga sekarang. Seperti penggunaan Ldr. Panjang Ilang Sl. Sanga untuk adegan Hutan Krendhawahana juga mendukung suasana sedih dan susah. Untuk mendukung suasana kaget, greget, dan marah cukup dengan sampak dan srepeg. Purbo Asmoro (Asmoro, Wawancara 2, 2019) tidak memaksakan penggunaan gending tertentu di dalam suatu adegan. Aspek yang paling penting baginya adalah dalang dapat menyampaikan pesan-pesan yang terkandung dalam lakon dan rasa yang dihasilkan gending bisa mendukung adegan. Misalnya penggunaan gending thutur, jikalau rasa sedih yang dihasilkan kuat dari nada sléndro maka penggunaan gending tidak dipaksakan dengan nada pélog.

\section{Bentuk Catur (Penceritaan oleh Dalang)}

Penceritaan dalang dalam lakon Aji Pamasa meliputi pembawaan, penyampaian, dan penyajian cerita di dalam pertunjukan wayang. Media drama dalam dunia pedalangan dikenal dengan unsur garap pakeliran yang disebut dengan catur. Catur merupakan semua wujud bahasa atau wacana yang diucapkan oleh dalang dalam pakeliran (Murtiyoso, 1981, p. 6). Menurut pedalangan gaya Surakarta 
catur terdiri atas tiga golongan, yaitu janturan, pocapan, dan ginem (Murtiyoso \& dkk., 2007, p. 10).

Purbo Asmoro (Wawancara 2, 2019) menyatakan bahwa dalam penyajian lakon ia meramu dua lakon menjadi satu runtutan cerita dengan harapan runtutan peristiwa dalam lakon menjadi jelas. Hal ini dimaksudkan agar penonton lebih mudah dalam memahami atau mengikuti cerita yang disajikan. Dalam kaitannya dengan penyajian lakon seperti yang telah dikemukakan tadi, maka garap catur menjadi unsur yang perlu diperhatikan.

Berdasarkan penelisikan terhadap lakon $A j i$ Pamasa Ki Purbo Asmoro, garap pakeliran yang berujud catur yang meliputi janturan, pocapan, dan ginem dapat dikemukakan sebagai berikut.

\section{Janturan}

Janturan adalah wacana dalang berupa deskripsi suatu adegan yang sedang berlangsung, mencakup suasana tempat (negara), tokoh, dan peristiwa dengan diiringi sirepan gending. Janturan merupakan bagian dari unsur catur yang berkedudukan sebagai wacana deskriptif suatu adegan ataupun peristiwa tertentu yang menggunakan medium ungkap bahasa (Murtiyoso \& dkk., 2007, p. 10).

Janturan secara garis besar memiliki dua fungsi yaitu fungsi teknik dan fungsi estetik. Secara teknik janturan mendeskripsikan suasana sesuatu yang belum terungkap lewat sarana ekspresi dramatik lainnya. Selain itu janturan juga memperjelas penampilan gambaran, baik mengenai tokoh, tempat, suasana, maupun peristiwa. Secara estetik, janturan berfungsi untuk membuat suasana atau kesan tertentu, dan mempertebal kesan dan / atau suasana yang telah muncul. Apabila ditinjau dari proporsi ungkapannya, janturan dapat dibedakan menjadi janturan ageng dan janturan alit. Janturan ageng yaitu janturan yang proporsi ungkapannya cukup panjang, biasanya digunakan dalam adegan pertama atau biasa disebut jejer dalam pakeliran semalam. Janturan alit yaitu janturan yang proporsi ungkapannya relatif pendek, biasanya digunakan dalam adegan-adegan setelah jejer pertama (Murtiyoso \& dkk., 2007, p. 11).

Seperti halnya janturan dalam pertunjukan wayang purwa, dalam pertunjukan wayang madya lakon Aji Pamasa ini janturan juga ditempatkan hampir di setiap adegan. Berikut petikan janturan pada adegan kerajaan Mamenang, adegan padepokan Gunung Kelud, dan adegan hutan Gunung Kawi.

Janturan adegan Kerajaan Mamenang: mendeskripsikan keadaan dan situasi sidang pertemuan di sitinggil.

Tidhem premanem datan ana sabawané walang alisik, nadyan gegodhongan tan ana obah samirana datan ana lumampab ingkang samya sumiwi wonten sitinggil binaturata kèndelan kéwala. Wingit pangaribawané Sang Nata Prabu Aji Pamasa temah akarya geter jroning paséwakan agung ingkang munggwing ayun, mabukub susilaharja nenggib patih nata minangka warangka tuwanggana nenggih kyai Patih Tambakbaya. Senadyan ta sang nata amung kèndelan kéwala parandéné uga datan kawiijl aturé, sadaya mubung sami anglangut ngumbar gagasan (Asmoro, 2018, pts. 00:17:11-00:18:25).

Terjemahan:

('Suasana begitu tenang tak ada suara yang terdengar, dedaunan pun tak bergerak, angin juga tak bertiup, mereka yang sedang menghadap di sitinggil hanya diam membisu. Perbawa Sang Raja Prabu Aji Pamasa yang luar biasa, menyebabkan suasana tegang di balai penghadapan, dia yang menghadap paling depan adalah sang perdana menteri, Patih Tambakbaya. Demikian juga Sang Raja hanya berdiam diri saja tak mengeluarkan sepatah kata pun, semua hanya mengumbar gagasan').

Dari petikan janturan negara Mamenang di atas, dapat dikatakan bahwa janturan yang digunakan cukup singkat, langsung mendeskripsikan suasana tenang, agung baik tentang sang raja maupun mereka yang menghadap di sitinggil.

Janturan adegan Gunung Kelud: mendeskripsikan situasi dan kondisi pertapaan.

Jenjem kang samya dedunung jenak ingkang sami andhedhépok anenggih ingkang angasrama ana lengkèb-lengkèbaning arga punika warnané Sang Ajar Téjalaku uga ana kang amastani Resi Téjalaku. Wegig waskitha ing ngèsthi mumpuni agal miwah lembat datan mokal lamun ta akèb cantrik manguyu jejanggan, indhung-indhung ulu guntung miwah para siswané. Nadyan ta sedaya mung dumadi saka wong ndésa miwah wong-wong 
ing pagunungan parandéné samya kasinungan jïwa utama teteken kasucèn pepayung budi rabayu. Kang munggwing ngayun nenggib prasasat kembar siswanira ingkang kinasib Kaniyasa miwah Kanigara datan kantun sowanira sang Janggan Babiri maksib kathah siswané Sang Ajar Téjalaku, Resi Domba, miwah Cèkèl Indra. Dadya mangkana panglocitané lamun ta kababar ing lésan (Asmoro, 2018, pts. 00:43:37-00:45:24).

Terjemahan:

('Semua betah tinggal di padepokan Sang Resi Tejalaku atau biasa disebut juga Ajar Tejalaku yang berada di lereng gunung. Sang ajar adalah seorang yang pintar dan berbudi luhur, mumpuni ilmu kasat mata dan tak kasat mata, oleh karena itu banyak murid yang berguru padanya. Walaupun mereka hanya berasal dari desa serta orang-orang pegunungan namun mereka berjiwa utama, suci dan berbudi luhur. Yang berada di hadapannya adalah dua orang murid yang bagai pinang dibelah dua, mereka murid terkasih bernama Kaniyasa dan Kanigara. Tidak mau ketinggalan Janggan Bahiri dan masih banyak para murid lain sang Resi Tejalaku, seperti Resi Domba dan Cekel Indra. Demikianlah gagasan dalam hati bila diungkapkan secara lisan').

Janturan untuk adegan di Gunung Kelud jika diperhatikan tidak jauh berbeda dari janturan di negara Mamenang. Janturannya singkat, padat, dan bahasanya sederhana. Rupa-rupanya hal ini sesuai dengan apa yang dikatakan Purbo Asmoro di depan, bahwa yang dikejar dari pergelarannya adalah penonton memahami apa yang disajikan.

Janturan adegan Gunung Kawi: mendeskripsikan Gunung Kawi dan Dua Naga.

Suwara gumuruh gumleger saking Gunung Kawi tuwuh saka pangaribawané kang mbaureksa Gunung Kawi nenggib sawer gung ingkang jejodhowan awasta Sang Naga Kunta lan Naga Kunti. Saka gedhéné nganti pethité naga nggubet pucuking gunung, cangkem mangap kaya kukus nggembuleng nyembur anutup pucuking arga, ilat cawang mèlèt mawa iler ndlèdèk kaya lahar anyembur mili nrajang wetenging gunung, satunggal kéwala datan ana manungsa kang wani ngambah pucaking Ardi Kawi. Labet gawat keliwat wingit kepati-pati, hawa panas ngubengi harga, godhong alum, kayu garing, kéwan-kéwan isining Gunung Kawi samya keplayu mangandhap, yekti datan ana kang kuwawa nampi pangaribawané sang naga diyu. Hanenggih Sang Naga Kunta lan Naga Kunti samya nedheng ketaman mungkaring manah ketaman nenggih sang naga Lanang. Dadya mangkana ingkang wadon amung tansah angreripib (Asmoro, 2018, pts. 03:17:13-03:18:55).

Terjemahan:

(Suara gemuruh menggelegar dari Gunung Kawi disebabkan oleh daya kekuatan dia yang menunggu Gunung Kawi yaitu sepasang ular besar bernama Naga Kunta dan Naga Kunti. Disebabkan oleh begitu besarnya, ekor naga itu melilit sampai mencapai puncak gunung, mulutnya selalu menganga menyemburkan asap yang bergulung-gulung hingga menutup puncak gunung, lidahnya yang bercabang menjulur berliur meleleh bagai lahar menyembur meleleh ke bawah menerjang perut gunung, tak satu pun manusia yang berani menginjakkan kaki di puncak Gunung Kawi. Karena sangat menakutkan dan menyeramkan, hawa panas menyelimuti gunung, dedaunan layu dan kering, hewanhewan di gunung Kawi semua mengungsi ke pemukiman karena tidak kuat dengan daya kekuatan sang naga raksasa. Demikianlah sang Naga Kunta dan Kunti, pada saat itu si naga jantan sedang marah sementara itu sang betina berusaha menenangkannya.')

Janturan adegan Gunung Kawi tidak berbeda dengan janturan adegan di negara Mamenang dan janturan adegan padepokan Gunung Kelud. Ketiganya diungkapkan dengan bahasa yang singkat, padat, dan jelas. Jika diperhatikan ketiga janturan memiliki nuansa yang sama dalam hal mendeskripsi situasi dan suasana adegan yang sedang berlangsung di kelir. Ketiganya dapat dikatakan menggunakan formula yang sama yaitu deskripsi tempat, tokoh, dan situasi/pokok permasalahan dalam adegan.

\section{Pocapan}

Pocapan adalah wacana dalang berupa narasi yang pada umumnya menceritakan peristiwa yang sudah, sedang, dan akan berlangsung, tanpa iringan gending sirepan. Apabila dilihat dari ungkapannya, 
pocapan sangat berbeda dengan janturan. Perbedaan itu terletak pada penggunaan bahasanya yang lebih sederhana jika dibanding janturan (Murtiyoso \& dkk., 2007, p. 14).

Secara teknik pocapan berfungsi sebagai sarana untuk memberikan penjelasan kepada penonton tentang hal yang sudah, sedang, dan akan terjadi. Adapun secara estetik pocapan berfungsi sebagai pendukung atau pembentuk suasana suatu peristiwa (Murtiyoso \& dkk., 2007, p. 15). Berikut adalah pocapan-pocapan yang dipetik dari lakon Aji Pamasa Ki Purbo Asmoro.

Pocapan Flashback: mendeskripsikan perasaan batin tokoh Aji Pamasa.

Sunaré bagaskara surem, wanciné angslup ing brang kulon lamat-lamat kidung layung karya lam-lam kumléyang godhong garing gogrok sakenggon-enggon. Sandyakala kalané nerak ingkang ana sesawangan sarwa garing lemab nela hawa panas mimbubi sumpeking ati kang nedheng jumeneng jegreg pindha pratima rukmi nenggih Ratu Mamenang kang kaping gangsal narendra ing Mamenang ya ing Kedhiri Prabu Aji Pamasa ya Sang Kiswara ya Sang Nata Prabu Kusumawicitra ya Sang Nata Halidrawa. Gumyur pangangen-angené tyasé baliwur suk-sukan rasané, anané mung kaya nekem asta getem-getem angendhem ati njarem. Raos kridha nunjem telenging ati wimbuh kaya kogel kagelaning galih alisé gathuk waja gathik ginegetgeget saking agengé muntab, murkaning manah amargi dumadiné lelakon kang anèb hanempub kedhaton Mamenang nadyan wus kapungkur nanging tansah nabet ing lelamunan (Asmoro, 2018, pts. 00:05:15-00:07:05).

Terjemahan:

('Sinar matahari mulai redup, pada saat tenggelam di sebelah barat. Samar-samar terdengar tembang kesedihan membuat nelangsa, daun-daun melayang jatuh dimanamana. Senjakala datang menerjang semua yang ada, semua tampak serba kering, tanah kering pecah-pecah terbelah, udara terasa panas menambah kesedihan hati dia yang sedang berdiri seperti arca emas, dialah raja Mamenang yang kelima, raja Kedhiri Prabu Aji Pamasa, yang juga disebut Prabu Kiswara, Prabu Kusumawicitra, sang Raja Halidrawa. Pikirannya sedang kacau bingung bercampur aduk. Hatinya diliputi kemarahan dan sakit hati. Kemarahan dan kekecewaan yang menghunjam hati tampak dari alisnya yang mengkerut, giginya yang gemeretak oleh kemarahan. Kemarahan yang ditimbulkan oleh terjadinya peristiwa aneh yang melanda Kerajaan Mamenang, walau sudah berlalu namun tetap menjadi pikiran').

Pocapan di awal pertunjukan ini hendak menjelaskan kepada penonton tentang "bibit" plot yang akan digelar dalam lakon ini. Pocapan ini memberi informasi bahwa peristiwa-peristiwa yang dijalin berawal dari sini, dari kemarahan raja Mamenang, Prabu Aji Pamasa. Ungkapan dalam pendeskripsian lebih pada kata-kata yang melukiskan keadaan batin sang tokoh.

Pocapan menunjukkan ulah Naga Kunta di Kerajaan Kediri.

Naga Kunta kang njedhul saka jro bumi. Mèlèt ilaté nyembur banyu muncrat mblabar ngiwa nengen angslup malih Sang Naga diyu nanging ngriku dadi sumbering tuk banyu saya gedhé wetuning toya, alun-alun dadi tlaga saya mumbul saya mumbul (Asmoro, 2018, pts. 03:51:02-03:51:25).

Terjemahan:

Naga Kunta yang muncul dari dalam bumi menjulur lidahnya menyemburkan air mengalir ke kanan dan ke kiri, masuk lagi ke dalam bumi Sang Naga Diyu, di situ kemudian menjadi sumber mata air semakin besar keluarnya air, alun-alun menjadi danau semakin naik dan semakin naik air itu).

Pocapan ini memberikan keterangan kepada penonton tentang ulah naga Kunta ketika membuat kekacauan di negara Kediri. Sang naga muncul dari dalam bumi lalu masuk lagi. Di situ kemudian menyembur air dari dalam bumi, yang semakin lama semakin banyak sehingga mengakibatkan banjir melanda kerajaan. Pocapan ini rupa-rupanya digunakan untuk membantu menajamkan imajinasi penonton, karena peristiwa banjir tidak dapat dihadirkan langsung di kelir.

Pocapan menunjukkan keadaan Kerajaan Mamenang setelah dilanda banjir lahar.

Wong-wong sami bubar pating jlerit, udan gedhé telung dina telung bengi niba, wimbuh saya ndedel tekaning banyu banjir, sitinggil kraton wus pèrès, cukat Patib Tambakbaya nyaut garwa ratu ingkang nyatané Naléndra Mamenang wus 
sawetara wanci datan katingal awit hamburu kang Maésayaksa. Gègèr jroning kedhaton, wewangunan omah-omah mung katon gendhèngé parandéné toya maksih trus mumbul, kumambang pating glimpang éwon cacahé kawula dadi korban Kedhiri kèlem, Hé Kedhiri kèlem! (Asmoro, 2018, pts. 03:52:3403:53:24).

\section{Terjemahan:}

('Para penduduk berlarian sambil berteriak, hujan deras tiga hari tiga malam, menambah semakin deras datangnya air banjir, sitinggil kerajaan sudah tenggelam, tanggap patih Tambakbaya menyelamatkan permaisuri dan putra raja, sementara Sang Raja tidak terlihat karena sedang memburu Maesayaksa. Porak poranda dalam kerajaan, bangunan rumahrumah hanya kelihatan atapnya sementara air masih terus bertambah, terapung-apung ribuan mayat korban tenggelamnya Kediri, Hai Kediri tenggelam!').

Pocapan ini menerangkan kepada penonton/pendengar tentang situasi dan keadaan orang-orang di kerajaan Kediri ketika dilanda banjir dan hujan yang mengguyur kerajaan selama tiga hari. Selain itu juga menjelaskan peristiwa penyelamatan permaisuri dan putranya oleh patih Tambakbaya. Seperti halnya pocapan tentang ulah naga Kunta, pocapan ini rupa-rupanya juga dimaksudkan untuk membantu penonton/ pendengar menajamkan imajinasinya.

Pocapan menunjukkan kesedihan Prabu Aji Pamasa atas bencana yang menimpa negaranya.

Rojah-rajèh lir rinajang-rajang tyasé Sang Aji Pamasa kaya linolosan salirané klintuning gunem sakecap tindak sejangkah nggondhol korban negara sakisiné mung tumungkul luh tumètès nelesi pangarasan rasanè wus kaya tanpa guna uripé muspra sugengé déné mung dadi jalaran patiné para kawulané kèleming negarané. Jibeging raos tanpa kumecap anané amung nutuh dhiri (Asmoro, 2018, pts. 05:23:22-05:24:21).

Terjemahan

(Hancur seperti diiris-iris hati sang Aji Pamasa lemas tak berdaya tubuhnya salah ucap serta salah langkah yang tidak seberapa membawa korban negara seisinya, ia hanya menunduk, air matanya menetes membasahi pipi, ia merasa sudah tiada guna hidupnya, karena hanya menjadi sebab para rakyat mati, negaranya tenggelam. Penyesalan dan kekecewaan membuat dirinya tak dapat berkata-kata, ia hanya bisa menyalahkan diri sendiri').

Pocapan tadi menjelaskan kepada penonton/pendengar tentang perasaan Aji Pamasa menyaksikan kehancuran negaranya karena kesalahan kecil yang dia lakukan. Sang dalang rupanya-rupanya ingin mengajak penonton untuk ikut merasakan apa yang dirasakan oleh Aji Pamasa lewat pocapan ini.

\section{Ginem}

Ginem adalah ucapan dalang yang mengekspresikan wacana tokoh wayang, baik dalam bentuk monolog maupun dialog. Apabila ditinjau dari tokoh atau pemerannya, ginem dapat dibedakan menjadi dua bentuk yaitu monolog dan dialog. Misalnya tokoh bergumam, ngudarasa, berbicara sendiri tanpa ada lawan bicaranya, ini termasuk ginem monolog. Kemudian ginem dalam bentuk dialog yaitu wacana wayang yang melukiskan pembicaraan antara dua tokoh wayang atau lebih yang mempunyai karakter berbeda-beda (Murtiyoso \& dkk., 2007, p. 16).

Ginem dalam pakeliran mempunyai fungsi untuk mengungkapkan permasalahan dalam lakon lewat wacana tokoh sesuai dengan kedudukannya dalam lakon. Selain itu ginem juga mengungkapkan perwatakan tokoh-tokoh sesuai dengan karakter masing-masing (Murtiyoso \& dkk., 2007, p. 18). Berikut petikan-petikan ginem yang terdapat dalam lakon Aji Pamasa Ki Purbo Asmoro.

Ginem konflik antara Wirabaya dengan Kaniyasa menunjukkan bantab/adu mulut antara kedua tokoh.

Kaniyasa : "Keparat panuksmané jajal laknat kowé punggawa negara nggon pranatan nanging kuduné ngerti tatanan. Kowé wani matèni wong tanpa mbok adili."

Wirabaya : "Perkarané wis cetha aku wenang ngadili kanthi ukum pati."

Kaniyasa : "Yèn ngéné iki carané iki dudu negara aku sing ora trima."

Wirabaya : "Wong cilik mungsuh negara dadi entup kowé, takobong ora dha minggat lan teluk. karo aku bakal takobong!"

Kaniyasa : "Panasing genimu ora bisa ngungkuli panasé atiku.” (Asmoro, 2018, pts. 
01:12:48-01:13-26).

Terjemahan:

Kaniyasa : "Keparat, kamu pejabat negara, yang membuat peraturan seharusnya mengerti aturan. Kamu berani membunuh orang tanpa diadili."

Wirabaya : "Masalahnya sudah jelas aku berwenang mengadili dengan membunuhnya."

Kaniyasa : "Kalau begini caranya, ini bukan negara namanya, aku yang tidak terima."

Wirabaya : "Rakyat jelata melawan negara tidak ada apa-apanya, akan kubakar kalau tidak segera pergi dan takluk kepadaku, akan kubakar!"

Kaniyasa : "Panas apimu tidak bisa melebihi panasnya hatiku."

Ginem Bathari Kalayuwati yang menyampaikan kabar pada Aji Pamasa bahwa anak kesayanganya hilang.

Aji Pamasa : "Pukulun lajeng kadospundi anak saba kulawarga kula?"

Kalayuwati: "Tujuné nalikea banyu durung gedhé patibmu si Tambakbaya bisa milujengaké kabèb bojo-bojomu lan putra-putramu."

Aji Pamasa : "Pukulun ngaturaken gunging panuwun."

Kalayuwati : "Nanging kowé aja seneng luwih dhisik Aji Pamasa, lan aja kagèt atimu anakmu siji si Citrasoma ilang kéntir ing banyu sakyahéné durung ketemu." (Asmoro, 2018, pts. 05:21:43-05:22:43).

Terjemahan:

Aji Pamasa : "Pukulun lalu bagaimana anak dan kulawarga saya?"

Kalayuwati : "Beruntung sekali ketika air belum begitu banyak, patihmu si Tambakbaya dapat menyelamatkan semua istrimu dan anak-anakmu."

Aji Pamasa : "Pukulun kuucapkan banyak terima kasih."

Kalayuwati : "Tetapi kamu jangan gembira dulu Aji Pamasa, dan jangan terkejut salah satu anakmu yaitu si Citrasoma hanyut dan hilang, hingga sekarang belum dapat ditemukan."
Ginem Prabu Aji Pamasa dengan Saktriya pada adegan babad Pengging, menunjukkan maksud dan tujuan Aji Pamasa yang ingin membangun kerajaan baru.

Saktriya : "Drubun karepmu ki apa sadurungé aku béla patiné sedulurku aku tak péngin weruh karepmu apa koke kowé mbabadi wewengkon ikiki!"

Aji Pamasa : "Ngertia aku bakal mujudaké papan iki minangka kutha gara lan praja kang kebak. kamulyan."

Saktriya : "Ah kok gampang temen guneman nalaré piyé?! Kowé arep gawé praja gawé negara?! Apa rumangsamu gawé negara pénak padha gawé gubug ngono pa piyée!"'

Aji Pamasa : "Gegaranku mung tekad lan kapercayan, percayaku marang panguwasané kang maka wikan."

Saktriya : "Ora mung tekad waé, kekendelan sing mbok darbèni nanging kowé kudu nduwé dasar sing nyata kanggo adeg-adeg negara Jawa."

Aji Pamasa : "Bumi kang takpidak iki nugrahané pangéran nugrahané kang maha agung marang titabé nadyan ta aku dudu wong kéné, nanging aku nduwé kuwajiban ngreksa mbangun wujud wewengkon kanggo tetumangkaré kamulyan lan undhaking panguripan ingkang kebak katentreman dhasar-dhasar kang kuat kanggo sentosaning praja ora ana liya kejaba ngakoni lamun ta titah iku ana kang anitahaké sakbanjuré gedhéning rasa katresnan kebak ing rasa tansah nggegulang rasa asih yekti bakal mbabar katentreman. Ndarbèni rasa tunggal lan tetunggalan rumangsa ndarbèni wajib ngrungkebi kang sarta mulad sarira hangrasa wani sakterusé sakrupané perkara kudu luwih rinembug kanthi pasarujukan ing wekasané ayo nyipta adil lan bener jejeging ukum lan ganjar ambudi murih mulyaning sasama."

Saktriya : "Ho ladalah... becik temen karepmu biyoh nèk ngono kaé aja ning nggon iki ning rada rana babadana kaé jenengé wewengkon Witaradya kaé ranaa kaé mlebua rana kaé." (Asmoro, 2018, pts. 06:10:5506:13:25). 
Terjemahan:

Saktriya : "Keparat... maksudmu apa?! Sebelum aku perang tanding denganmu demi saudaraku, aku pengin tahu, apa maksudmu menebangi hutan di wilayah ini?!"

Aji Pamasa : "Ketahuilah aku akan mendirikan sebuah kerajaan yang makmur sejahtera di tempat ini."

Saktriya : "Ah enak sekali omonganmu, bagaimana caranya mau mendirikan sebuah kerajaan?! Kau kira mendirikan kerajaan itu semudah mendirikan gubug?!'

Aji Pamasa : "Bekalku hanya tekad dan percaya, percaya pada kekuasaan Tuhan."

Saktriya : "Tidak hanya tekad dan keberanian saja, tetapi kamu harus punya dasar yang kuat untuk pegangan negara Jawa."

Aji Pamasa : "Bumi yang kuinjak ini anugerah Tuhan Yang Maha Agung kepada semua makhluknya, meski aku bukan orang sini, tetapi aku punya kewajiban menjaga dan mendirikan kerajaan yang makmur dan sejahtera, tenteram lahir batin. Dasar yang kuat untuk kesentosaan negara tak lain dan tak bukan adalah pengakuan bahwa makhluk itu ada yang menciptakan, selain itu kasih sayang dan kepedulian akan mendatangkan ketentraman. Persatuan dan kesatuan serta merasa memiliki, percaya diri dan segala masalah dimusyawarahkan pasti keadilan akan terwujud, demi kesejahteraaan bersama."

Saktriya : "Ho ladalah... bagus sekali tujuanmu, baiklah jika demikian sana... jangan di tempat ini, agak ke sana tebangilah hutan di wilayah Witaradya, masuklah ke sana!'

Ginem tokoh Semar yang berisikan nasihat dan amanat yang terkandung dalam lakon.

Semar : "E... mboten napa-napa sedaya ingkang lumampah punika tartamtu sampun saking budidayané manungsa piyambak upamané ndika lepat nggih lepaté manungsa. Senadyan sampun ginaris lampabing kodrat manungsa amung wenang ambudidaya ning ngaten nggih Sinuwun rèbning sakmangké sampun purna ing lampab kula mung badhé meling pancadriya ingkang bludag ambraambra niku dadi pepalang gedhé tumrap sedya manembah napsuning pancadriya wau sarupaning pepénginan ingkang tumanduk dhateng raos énak lan kepénak sing njalari lali marang sejatiné uripé karem dhahar main minum madat madon maoni maling niku wis dadi pepali sing kudu disingkiri ugi pakulinan ingkang saged damel regeding manah asoring budi mèrèn dahwèn lan sanèssanèsipun. Namung nyatanipun manggamangga dipunsuraos awit lelampahaning titah punapa kéwala sedaya amung saged dipunorak-arik wonten jagadipun piyambak-piyambak." (Asmoro, 2018, pts. 06:24:18-06:26:20).

Terjemahan:

Semar : "E... nggak apa-apa semua yang terjadi ini tentu karena ulah manusia itu sendiri, seumpama anda salah itu masih manusiawi. Semua telah digariskan manusia hanya menjalani. Begini Sinuwun karena sekarang semua telah selesai saya hanya berpesan bahwa nafsu pancaindra yang tak terkendali itu merupakan penghalang besar bagi tujuan sembah kita. Segala keinginan yang melenakan menjadi penyebab lupa akan kesejatian hidup. Gemar makan minum madat main dan mencuri milik orang lain itu larangan yang harus dijauhi. Begitu juga segala kebiasaan yang menyebabkan kotornya hati seperti cemburu, iri, dengki, dan rendahnya budi pekerti. Marilah kita bersamasama renungkan bahwa perjalanan hidup manusia itu hanya dapat diubah dalam dunianya masing-masing."

\section{Garap Pakeliran Lakon Aji Pamasa Ki Purbo Asmoro}

Pada pertunjukan wayang madya lakon $A j i$ Pamasa ini, Ki Purbo Asmoro melakukan garap lakon, garap sabet, garap iringan, dan garap 
penokohan.

Garap penokohan tampak pada adegan Naga Kunta dan Naga Kunti. Pada sumber cerita atau balungan konvensional masalah yang dipaparkan tidak begitu jelas dan tidak tersambung. Oleh karena itu Purbo Asmoro (Asmoro, Wawancara 3, 2018) menambah adegan yang mendukung sehingga cerita menjadi logis dan menarik. Selain itu penambahan alur cerita juga terdapat pada adegan kematian Tejalaku oleh Wirabaya. Sanggit konvensional tidak cukup jelas alur ceritanya kemudian oleh dalang dibuatlah sanggit cerita Wirabaya yang berguru terlebih dahulu dengan Resi Tejalaku.

Dalam hal garap lakon Purbo Asmoro mengacu pada konsep padat dan nilai-nilai yang disampaikan dalam lakon ini disesuaikan dengan kehidupan zaman sekarang (kontekstual). Tentang cara pandangnya atau pemaknaannya terhadap sebuah nilai, disampaikan melalui tanda dirobohkannya pohon rejasa pada adegan flasback.

Tentang garap iringan, dalam lakon Aji Pamasa ini dibuat seperti iringan wayang purwa pada umumnya. Penggunaan iringan seperti halnya wayang purwa, diakui oleh Purbo Asmoro, lebih pada pertimbangan iringan tersebut telah akrab di telinga penonton/pendengar.

Garap sabet diolah berdasarkan balungan lakon yang dibuat. Penggunaan sabet tematik hanya terdapat pada flashback saja selain itu digunakan sabet representatif.

\section{Simpulan}

Tulisan ini menghasilkan sebuah kajian tentang sanggit/garap lakon Aji Pamasa Ki Purbo Asmoro. Kajian ini menghasilkan sebuah simpulan bahwa pertunjukan wayang madya lakon $A j i$ Pamasa sanggit Ki Purbo Asmoro telah mengalami penyesuaian dalam beberapa hal, antara lain boneka wayang menggunakan boneka wayang purwa yaitu wayang srambahan; iringan pakelirannya menggunakan laras pélog dan laras sléndro. Adapun unsur-unsur garap pakeliran sanggit $\mathrm{Ki}$ Purbo Asmoro dalam lakon Aji Pamasa meliputi: garap lakon, garap sabet, garap iringan, dan garap penokohan.

\section{Kepustakaan}

Asmoro, P. (2018). Wayang Madya “Ajipamasa” Ki Purbo Asmoro, S.Kar.,M.Hum. In Punakawan.

https://www.youtube.com/watch?v=EEOF MPVRGFU

Asmoro, P. (2019, Maret 25). Wawancara 1. (S. Adi, Interviewer) Surakarta, Jawa Tengah, Indonesia.

Asmoro, P. (2019, April 28). Wawancara 2. (S. Adi, Interviewer) Surakarta, Jawa Tengah, Indonesia.

Asmoro, P. (2018, Desember 3). Wawancara 3. (S. Adi, Interviewer) Surakarta, Jawa Tengah, Indonesia.

Murtiyoso, B. (1981). Pengetahuan Pedalangan. ASKI.

Murtiyoso, B., \& dkk. (2007). Teori Pedalangan: Bunga Rampai Elemen-elemen Dasar Pakeliran. ISI Surakarta dan CV Ska Production.

Nugroho, S. (2012). Lakon Banjaran: Tabir dan LikaLikunya Wayang Kulit Purwa Gaya Surakarta. ISI Press.

Putra, D. S. (2019, Maret 21). Wawancara. (S. Adi, Interviewer)

Soetarno. (2004). Wayang Kulit: Perubahan Makna Ritual dan Hiburan. STSI Press.

Soetarno, Sunardi, \& Sudarsono. (2007). Estetika Pedalangan. ISI Surakarta dan CV Adji Surakarta.

Soetrisno, R. (1985). Mengungkap Kembali Wayang Madya.

Suwarno, B. (2015). W anda Wayang Purwa Tokoh Pandhawa Gaya Surakarta Kajian Bentuk, Fungsi, dan Pertunjukan. Program Pasca Sarjana, UGM. 